\title{
Effects of Different Horticultural Substrates Composition and Depth on Runoff Water Quality
}

\author{
HAO Shuai ${ }^{1, a}$, ZHU Yihe ${ }^{1, b}$, WANG Shunli ${ }^{* 1,2, c}$, \\ Liu Kefeng 1, 2, d, zhang Qiang ${ }^{1, e}$ \\ ${ }^{1}$ Beijing University of Agriculture, Beijing, China, 102206 \\ ${ }^{2}$ Key Laboratory of Urban Agriculture(North China), Ministry of Agriculture, P.R. China \\ a260433900@qq.com, b937165808@qq.com, ${ }^{\text {c* } \quad C o r r e s p o n d i n g ~ a u t h o r, ~ w a n g s h u n l i 80 @ 163 . c o m ~}$ \\ d liukefeng006@126.com e1422551393@qq.com
}

Keywords: Straw; Cow feces; Matrix;

Abstract. In this research, a new type of roof cultivation substrate with different ratios of six kinds of substrate products and inorganic substrates was laid in a self-made roof model with a thickness of $7.5 \mathrm{~cm}$ and $15 \mathrm{~cm}$, and the substrate was sprayed to record the matrix flow production time, the amount of runoff water, etc., then the water quality of the collected runoff was tested and a significant test was conducted. The results showed that with the increase of the depth of the same matrix, the storage capacity of the matrix is stronger. Finally, three more ideal matrix formulations were selected: T222 [V\{substrate product (V straw: V cow manure: V lignite $=12: 2: 4)\}: \mathrm{V}$ vermiculite: $\mathrm{V}$ fly ash $=2: 3: 3$ ] optimal, followed by T122 [V \{substrate product (V straw: V cow manure: $\mathrm{V}$ lignite $=12: 4: 2)\}: \mathrm{V}$ vermiculite: $\mathrm{V}$ fly ash $=2: 3: 3]$ and T422 [V $\{$ Substrates (V Straw: V Cow manure: $V$ peat $=12: 2: 4)\}$ : V Vermiculite: $V$ fly ash $=2: 3: 3]$.

\section{Introduction}

In the past three years, more than 360 cities have encountered waterlogging, and "every rain will fall" has become one of the major urban disasters in China. Sponge City has good "elasticity" in adapting to environmental changes and responding to natural disasters. One of the key technologies for the construction of Sponge City is to absorb and accumulate rainwater by laying a certain thickness of horticultural substrate on the city's roofs and garden level. In recent years, roof cultivation techniques have been widely used in developed countries such as Germany, the United States, and Japan. However, there are still some cities that have not yet developed roof cultivation facilities, in China. In addition to the first batch of pilot cities, the subsequent cultivation of urban rooftops is still less than $1 \%$. It can be seen that there is still a great deal of development in roof cultivation in China. Many studies abroad have shown that roof cultivation techniques have great ecological and environmental benefits. For example, roof cultivation techniques can retain rainwater, thereby prolonging the time for surface runoff and reducing the effects of waterlogging. At the same time, plants can absorb $\mathrm{CO}_{2}, \mathrm{CH}_{4}$ and other greenhouse gases and pollutants in the air to optimize air quality and reduce pollution and the effcet of urban heat island effect. However, there has been controversy over the study of the surface runoff water quality after roof cultivation. The main reason lies in the differences in the formula, depth and daily management of the roof cultivation matrix selected by the researchers. 
This study focused on the effects of roof cultivation substrates on surface runoff water quality and water volume. First, six kinds of new horticultural substrates were formulated from six kinds of agricultural and forestry waste matrix products, peat and pastoral soil, vermiculite and fly ash. Based on the simulated rainfall test, the depths of $7.5 \mathrm{~cm}$ and $15 \mathrm{~cm}$ of the two substrates were designed to analyze the retention capacity of the eight new horticultural substrates at different depths and the pollution degree of runoff water quality, and a more suitable light roof cultivation was selected. Matrix to provide scientific basis for the application and promotion of roof cultivation techniques.

\section{Materials and methods}

The experiment was conducted in the glass greenhouse of Beijing University of Agricultural.

\section{Experiment materials}

Raw materials included cow dung and corn stalks. Fresh cow dung was purchased from Beijiao farm in Beijing. Corn stalks were taken from Beijing University of Agricultural Experimental Base and crushed to 1 to $2 \mathrm{~cm}$. Additional excipients were as follows: homemade peat was purchased from Fengtai Flower and Wood Center in Beijing; lignite was acquired in suburban coal yard in Beijing, fly ash was acquired from Chengde Luanhe Power Plant.

The basic physical and chemical properties of additional excipients are shown as Table 1.

Tab. 1 Basic physical and chemical properties of additional excipients

\begin{tabular}{ccccc}
\hline Kinds of excipients & $\mathrm{pH}$ & $\mathrm{EC} /\left(\mathrm{mS} \cdot \mathrm{cm}^{-1}\right)$ & Total salt $/ \%$ & $\mathrm{TDS} /\left(\mathrm{mg} \cdot \mathrm{L}^{-1}\right)$ \\
\hline Lignite & 4.85 & 1.627 & 0.10 & 814.0 \\
Peat & 4.88 & 0.261 & 0.02 & 130.6 \\
Fly ash & 7.76 & 0.566 & 0.03 & 283.0 \\
\hline
\end{tabular}

\section{Experiment design}

On the basis of the results of early fermentation test of the research group, the volume ratio of corn straws to cow dung and auxiliary materials was 12:3:3 as a control (lignite as $\mathrm{C} 1$, peat as $\mathrm{C} 2$ ), and the total volume were kept constant. Four treatments are shown in Table 2.

Tab. 2 Composting program test

\begin{tabular}{ccc}
\hline Test & Fermenting component & Volume ratio \\
\hline T1 & corn stalks: cow dung: lignite & $12: 4: 2$ \\
T2 & corn stalks: cow dung: lignite & $12: 2: 4$ \\
T3 & corn stalks: cow dung: peat & $12: 4: 2$ \\
T4 & corn stalks: cow dung: peat & $12: 2: 4$ \\
C1 & corn stalks: cow dung: lignite & $12: 3: 3$ \\
C2 & corn stalks: cow dung: peat & $12: 3: 3$ \\
\hline
\end{tabular}

The matrix product or matrix is mixed with vermiculite and fly ash, and a self-designed simple roof model is used to load the matrix with different proportions and depths (Table 3), and then use the simple simulation sprinkler irrigation water collecting device to the matrix simulated rainfall of 1.8 $\mathrm{mm} / \mathrm{min}$ was carried out for $30 \mathrm{~min}$. Finally, the runoff water quality was collected and related pollution indicators were determined. 
Tab. 3 Experimental design of simulated irrigation

\begin{tabular}{ccc}
\hline Test & \multicolumn{1}{c}{$\begin{array}{c}\text { Matrix product or matrix: Vermiculite: Fly } \\
\text { ash (Volume ratio) }\end{array}$} & Substrate depth/mm \\
\hline Kind of fermentation & $1: 1: 1$ & 7.5 \\
Product or matrix & $2: 3: 3$ & 15.0 \\
\hline
\end{tabular}

Note: Fermentation product is product of T1-T4, C1 and C2. Matrix is domestic peat or garden soil. The code rule of the simulation irrigation experimental processing is Nxyz, where $\mathrm{Nx}$ stands for corresponding compost experimental code, y represents two different ratios of the matrix mixture, and $\mathrm{z}$ is two different thicknesses of the matrix.

\section{Experiment equipment}

The construction process of a simple simulation sprinkler irrigation water collecting device was as Figure 1. Firstly, a small hole is directly under the sorting box $(59 * 38 * 34 \mathrm{~cm})$ for collecting runoff water; secondly, a draining board (about $2 \mathrm{~cm}$ in thickness) is laid in the sorting box for drainage and to prevent large-grained matrix Drain; the last, a layer of geotextile was covered to prevent the loss of small particles such as sediment.

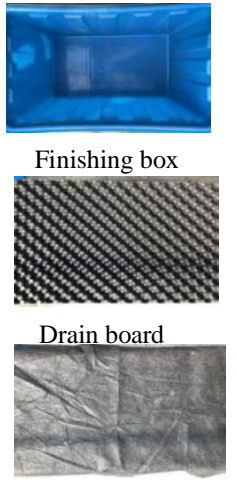

Geotextile

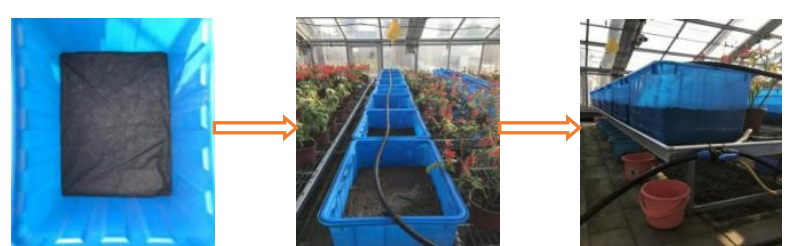

$59 \mathrm{~cm} * 38 \mathrm{~cm} * 34 \mathrm{~cm}$

Fig. 1 Simple simulation sprinkler irrigation water collecting device construction process

\section{Measurement indicators and methods}

Surface water pollutant indicators: COD, ammonia nitrogen, total phosphorus, $\mathrm{SS}, \mathrm{pH}, \mathrm{EC}^{[1]}$ and other indicators, are measured in accordance with national standards ${ }^{[2]}$.

Tab. 4 Indicators measuring instrument

\begin{tabular}{cc}
\hline Indicators & Instrument \\
\hline Flow time & Stopwatch \\
Lag time & Ruler \\
Runoff & ET 125 SC COD Rapid Tester \\
COD & Lianhua Science and Technology 5B-6C \\
ammonia nitrogen & Multi-parameter Water Quality Tester \\
total phosphorus & PHS-2F pH meter \\
SS & DDSJ-308A conductivity meter \\
pH &
\end{tabular}

\section{Data processing and analysis}

This study uses Excel 97-2003 and SPSS 22.0 software for statistical analysis and mapping. 


\section{Results and analysis}

\section{Water storage capacity of substrate}

The time of runoff can reflect water holding ability of the substrate during a period of time when it has been washed with water. In the simulated experiment, formation of runoff from the water-permeable substrate is later, and then the ability of water storage of matrix is better.

The volume of runoff can reflect the drainage of the matrix. The displacement is larger, the ability of the matrix of water retaining is weaker, and the contrary is stronger. It can explain the matrix retention capacity better. The retention rate can intuitively reflect the ability of the substrate to intercept water.

The results showed in table 5 indicated that the runoff time was prolonged, surface runoff became less, and the retention rate of the matrix on runoff was higher with the same kind of matrix deeper. In the mixed substrate formulation with matrix ratio of $1: 1: 1$ volume ratio of vermiculite and fly ash, T112 matrix has the best water storage capacity and is superior to peat, but lower than urea soil; The mixed matrix of the product ( $\mathrm{V}$ straw: V cow manure: $\mathrm{V}$ lignite= 12:3:3) had the best water storage capacity in the mixed matrix formulations and was superior to peat but lower than the pastoral soil.

Tab. 5 Runoff of different experimental treatments in simulated irrigation

\begin{tabular}{|c|c|c|c|c|c|}
\hline Test & Flow time/s & Runoff/mm & $\begin{array}{l}\text { Runoff } \\
\text { retention } \\
\text { rate/\% }\end{array}$ & $\begin{array}{c}\text { Average/ } \\
\%\end{array}$ & $\begin{array}{c}\text { Detention rate } \\
\text { increase } / \%\end{array}$ \\
\hline $\mathrm{T} 111$ & 832 & 28 & 48.1 & \multirow{2}{*}{58.3} & \multirow{2}{*}{20.4} \\
\hline $\mathrm{T} 112$ & 1350 & 17 & 68.5 & & \\
\hline $\mathrm{T} 211$ & 670 & 35 & 35.2 & \multirow{2}{*}{35.2} & \multirow{2}{*}{0.0} \\
\hline $\mathrm{T} 212$ & 668 & 35 & 35.2 & & \\
\hline C111 & 327 & 34 & 37.0 & \multirow{2}{*}{47.2} & \multirow{2}{*}{20.4} \\
\hline C112 & 957 & 23 & 57.4 & & \\
\hline T311 & 777 & 32 & 40.7 & \multirow{2}{*}{50.0} & \multirow{2}{*}{18.6} \\
\hline T312 & 1308 & 19 & 59.3 & & \\
\hline $\mathrm{T} 411$ & 585 & 38 & 13.0 & \multirow{2}{*}{21.3} & \multirow{2}{*}{16.6} \\
\hline $\mathrm{T} 412$ & 615 & 47 & 29.6 & & \\
\hline $\mathrm{C} 211$ & 327 & 34 & 22.2 & \multirow{2}{*}{25.9} & \multirow{2}{*}{7.4} \\
\hline $\mathrm{C} 212$ & 957 & 23 & 29.6 & & \\
\hline CK111 & 515 & 28 & 48.1 & \multirow{2}{*}{56.45} & \multirow{2}{*}{16.7} \\
\hline FCK112 & 1033 & 19 & 64.8 & & \\
\hline CK211 & 1045 & 24 & 55.6 & \multirow{2}{*}{75.0} & \multirow{2}{*}{38.8} \\
\hline CK212 & 1734 & 3 & 94.4 & & \\
\hline $\mathrm{T} 121$ & 913 & 27 & 50.0 & \multirow[t]{2}{*}{61.1} & \multirow[t]{2}{*}{22.2} \\
\hline $\mathrm{T} 122$ & 1202 & 15 & 72.2 & & \\
\hline $\mathrm{T} 221$ & 716 & 34 & 37.0 & \multirow[t]{2}{*}{44.45} & \multirow[t]{2}{*}{14.8} \\
\hline $\mathrm{T} 222$ & 930 & 26 & 51.9 & & \\
\hline C121 & 788 & 32 & 40.7 & \multirow[t]{2}{*}{50.9} & \multirow[t]{2}{*}{20.4} \\
\hline C122 & 1033 & 21 & 61.1 & & \\
\hline T321 & 808 & 30 & 44.4 & 54.6 & 20.4 \\
\hline
\end{tabular}




\begin{tabular}{cccccc} 
T322 & 927 & 22 & 64.8 & & \\
T421 & 807 & 33 & 38.9 & 44.45 & 11.1 \\
T422 & 887 & 27 & 50.0 & & \\
C221 & 587 & 38 & 29.6 & 41.65 & 24.1 \\
C222 & 970 & 25 & 53.7 & & \\
CK121 & 867 & 27 & 50.0 & 62.05 & 24.1 \\
CK122 & 1290 & 14 & 74.1 & & \\
CK221 & 1022 & 20 & 63.0 & 78.7 & 31.5 \\
\hline
\end{tabular}

In the mixed matrix formulation of the matrix product with the volume ratio of vermiculite and fly ash of 2:3:3, the matrix of T122 treatment had the best water storage capacity in each treatment, but was slightly lower than that of peat; the matrix product ( $\mathrm{V}$ cow manure: $\mathrm{V}$ straw: $\mathrm{V}$ lignite= 12:3:3) had the best water storage capacity in the mixed matrix formulations but was slightly lower than that of peat.

Tab. 6 Runoff retention capacity of different matrixes

\begin{tabular}{cccccccccc}
\hline $\begin{array}{c}\text { Matrix } \\
\text { ratio }\end{array}$ & $\begin{array}{c}\text { Substr } \\
\text { ate } \\
\text { depth }\end{array}$ & T1 & T2 & C1 & T3 & T4 & C2 & Peat & $\begin{array}{c}\text { pastora } \\
1 \text { soil }\end{array}$ \\
\hline \multirow{2}{*}{$1: 1: 1$} & 7.5 & 48.1 & 35.2 & 37.0 & 40.7 & 13.0 & 22.2 & 48.1 & 55.6 \\
& 15 & 68.5 & 35.2 & 57.4 & 59.3 & 29.6 & 29.6 & 64.8 & 94.4 \\
Average & - & & $46.9 \mathrm{bc}$ & & & $32.4 \mathrm{c}$ & & 56.45 & $75.0 \mathrm{a}$ \\
& 7.5 & 50.0 & 37.0 & 40.7 & 44.4 & 38.9 & 29.6 & 50.0 & 63.0 \\
$2: 3: 3$ & 15 & 72.2 & 51.9 & 61.1 & 64.8 & 50.0 & 53.7 & 74.1 & 94.4 \\
& & & $52.15 \mathrm{bc}$ & & & $46.9 \mathrm{c}$ & & 62.05 & $78.7 \mathrm{a}$ \\
Average & - & & & & & & & \\
\end{tabular}

Note: the same column data is marked with different lower case letters, indicating significant difference $(P<0.05)$.

From Table 6, it can be seen that the retention rate of the matrix to runoff water is higher with the increase of the ratio of the inorganic matrix added to the same kind of substrate product. The retention capacity of $\mathrm{T} 1$ and $\mathrm{T} 2$-treated matrix on runoff water was stronger than that of $\mathrm{T} 3$ and T4-treated matrix, but there was no significant difference between the two at the 0.05 level; both were lower than the retention capacity of the two control matrices, but the retention capacity of the T1 and T2-treated matrix. At 0.05 level the difference with peat was not significant. The reason for this phenomenon may be due to the higher water-holding pores of fly ash in the inorganic matrix. The retention capacity of the matrix increases with the increase of fly ash, and the matrix product is produced by fermentation of straw. High, therefore, the storage capacity of the substrate product is weaker than that of peat and pastoral soil.

\section{Contamination analysis of substrate}

As can be seen from Table 7, the matrix product was mixed with vermiculite and fly ash in a 1:1:1 volume ratio mixed matrix formulation. The mean concentrations of COD, ammonia nitrogen, total $\mathrm{P}, \mathrm{SS}$, and EC in the surface runoff of the two control matrices were Lower, and in line with the national surface water environment, Class V standards. In terms of COD concentration, the COD concentration of all treated substrates was significantly higher than that of the two controls and the 
content was excessive. In terms of ammonia nitrogen concentration, ammonia nitrogen content of the remaining substrates met the standard, except T31 and C21 treated substrates, which exceeded the standard, and T11and T21. The ammonia nitrogen content was not significantly different from that of peat moss CK21 at 0.05 level. In terms of total P concentration, the total P content of the rest of the treated substrates was in compliance with the exception that the total P content of the treated substrates of T11 and T31 was exceeded. In terms of SS concentration, only the SS content of the substrate treated with T11 and T21 was not significantly different from that of the two controls at the 0.05 level, and the other treatments were significantly higher than the two controls. In terms of $\mathrm{pH}$ value, all treatments reached the national surface water environmental quality class $\mathrm{V}$ standard, and the $\mathrm{pH}$ of field soil CK21was significantly higher than other substrates at the 0.05 level, T11 and $\mathrm{T} 41 \mathrm{The} \mathrm{pH}$ of the treated substrate was significantly higher at the 0.05 level than the poke moss CK11. In terms of EC value, except for T11and T21 treatments, EC values of the remaining treated substrates were significantly higher than those of the two controls at a level of 0.05 .

Tab. 7 Comparison of water quality parameters of matrix

\begin{tabular}{|c|c|c|c|c|c|c|}
\hline Text & $\begin{array}{c}\mathrm{COD} \\
\left(\mathrm{mg} \cdot \mathrm{L}^{-1}\right)\end{array}$ & $\begin{array}{l}\text { ammonia } \\
\text { nitrogen } \\
\left(\mathrm{mg} \cdot \mathrm{L}^{-1}\right)\end{array}$ & $\begin{array}{c}\text { P total } \\
\left(\mathrm{mg} \cdot \mathrm{L}^{-1}\right)\end{array}$ & $\mathrm{SS} /\left(\mathrm{mg} \cdot \mathrm{L}^{-1}\right)$ & $\mathrm{pH}$ & $\begin{array}{c}\mathrm{EC} / \\
\left(\mathrm{ms}^{\cdot} \mathrm{cm}^{-1}\right)\end{array}$ \\
\hline $\mathrm{T} 11$ & $47.50 \pm 9.59 \mathrm{c} *$ & $0.48 \pm 0.10 \mathrm{~d}$ & $\begin{array}{l}0.44 \pm 0.04 \mathrm{~b} \\
*\end{array}$ & $6.74 \pm 1.63 \mathrm{c}$ & $7.94 \pm 0.03 b$ & $\begin{array}{l}2.41 \pm 0.27 \mathrm{c} \\
\mathrm{d}\end{array}$ \\
\hline $\mathrm{T} 21$ & $63.75 \pm 12.59 \mathrm{c}^{*}$ & $0.65 \pm 0.26 \mathrm{~d}$ & $0.13 \pm 0.02 \mathrm{~d}$ & $4.08 \pm 0.59 \mathrm{c}$ & $7.68 \pm 0.01 d$ & $2.99 \pm 0.89 \mathrm{c}$ \\
\hline $\mathrm{C} 11$ & $\begin{array}{l}172.33 \pm 34.69 \\
b^{*}\end{array}$ & $1.54 \pm 0.09 \mathrm{c}$ & $0.20 \pm 0.01 \mathrm{c}$ & $\begin{array}{l}50.49 \pm 10.33 \\
\text { b }\end{array}$ & $7.70 \pm 0.03 \mathrm{~d}$ & $4.42 \pm 0.79 b$ \\
\hline T31 & $\begin{array}{l}240.17 \pm 24.55 \mathrm{a} \\
*\end{array}$ & $\begin{array}{l}2.02 \pm 0.09 \mathrm{ab} \\
*\end{array}$ & $\begin{array}{l}0.53 \pm 0.12 \mathrm{a} \\
*\end{array}$ & $\begin{array}{l}86.95 \pm 12.75 \\
\mathrm{a}\end{array}$ & $7.87 \pm 0.13 b c$ & $6.18 \pm 0.84 \mathrm{a}$ \\
\hline $\mathrm{T} 41$ & $\begin{array}{l}157.00 \pm 21.39 \\
b^{*}\end{array}$ & $1.88 \pm 0.08 b$ & $0.38 \pm 0.08 b$ & $41.54 \pm 6.22 b$ & $7.94 \pm 0.03 b$ & $4.30 \pm 0.30 \mathrm{~b}$ \\
\hline $\mathrm{C} 21$ & $\begin{array}{l}181.00 \pm 35.86 \\
b^{*}\end{array}$ & $2.12 \pm 0.24 \mathrm{a}^{*}$ & $0.20 \pm 0.04 c$ & $\begin{array}{l}82.80 \pm 12.45 \\
\mathrm{a}\end{array}$ & $\begin{array}{l}7.78 \pm 0.22 b c \\
d\end{array}$ & $4.91 \pm 1.24 b$ \\
\hline CK11 & $16.50 \pm 2.22 d$ & $0.53 \pm 0.02 \mathrm{~d}$ & $0.01 \pm 0.00 \mathrm{e}$ & $5.27 \pm 0.35 \mathrm{c}$ & $7.74 \pm 0.18 \mathrm{~cd}$ & $1.94 \pm 0.30 \mathrm{~d}$ \\
\hline CK21 & $18.83 \pm 1.21 \mathrm{~d}$ & $0.08 \pm 0.02 \mathrm{e}$ & - & $2.17 \pm 0.79 \mathrm{c}$ & $8.27 \pm 0.08 \mathrm{a}$ & $\begin{array}{l}2.31 \pm 0.27 \mathrm{c} \\
\mathrm{d}\end{array}$ \\
\hline $\mathrm{T} 12$ & $87.17 \pm 6.07 c^{*}$ & $0.64 \pm 0.18 b c$ & $0.26 \pm 0.22 \mathrm{a}$ & $10.08 \pm 4.50 \mathrm{~d}$ & $7.83 \pm 0.10 b$ & $\begin{array}{l}3.81 \pm 1.01 \mathrm{~b} \\
\mathrm{c}\end{array}$ \\
\hline $\mathrm{T} 22$ & $11.83 \pm 5.43 \mathrm{~d}$ & $0.38 \pm 0.15 c$ & $0.03 \pm 0.02 b$ & $2.66 \pm 0.86 \mathrm{e}$ & $7.64 \pm 0.19 \mathrm{c}$ & $\begin{array}{l}2.97 \pm 0.23 \mathrm{c} \\
\mathrm{de}\end{array}$ \\
\hline $\mathrm{C} 12$ & $113.83 \pm 4.22 \mathrm{c}^{*}$ & $1.27 \pm 0.35 \mathrm{a}$ & $0.32 \pm 0.30 \mathrm{a}$ & $24.84 \pm 6.22 \mathrm{c}$ & $7.56 \pm 0.03 \mathrm{~cd}$ & $4.79 \pm 1.00 \mathrm{~b}$ \\
\hline $\mathrm{T} 32$ & $\begin{array}{l}158.83 \pm 21.79 \\
b^{*}\end{array}$ & $1.45 \pm 0.14 \mathrm{a}$ & $0.37 \pm 0.13 \mathrm{a}$ & $54.35 \pm 0.81 \mathrm{a}$ & $7.97 \pm 0.03 \mathrm{a}$ & $\begin{array}{l}3.98 \pm 0.40 \mathrm{~b} \\
\mathrm{c}\end{array}$ \\
\hline $\mathrm{T} 42$ & $92.00 \pm 20.61 c^{*}$ & $0.80 \pm 0.07 \mathrm{~b}$ & $0.22 \pm 0.02 \mathrm{a}$ & $26.12 \pm 1.18 \mathrm{c}$ & $8.03 \pm 0.07 \mathrm{a}$ & $\begin{array}{l}3.12 \pm 0.40 \mathrm{c} \\
\mathrm{d}\end{array}$ \\
\hline $\mathrm{C} 22$ & $\begin{array}{l}267.67 \pm 87.91 \mathrm{a} \\
*\end{array}$ & $1.19 \pm 0.27 \mathrm{a}$ & $0.31 \pm 0.17 \mathrm{a}$ & $\begin{array}{l}35.10 \pm 10.04 \\
b\end{array}$ & $7.48 \pm 0.03 \mathrm{~d}$ & $5.78 \pm 1.35 \mathrm{a}$ \\
\hline CK12 & $22.83 \pm 5.21 \mathrm{~d}$ & $0.53 \pm 0.29 b c$ & $0.05 \pm 0.04 \mathrm{~b}$ & $4.26 \pm 1.33 \mathrm{de}$ & $7.65 \pm 0.13 c$ & $2.06 \pm 0.29 \mathrm{e}$ \\
\hline CK22 & $17.50 \pm 3.45 \mathrm{~d}$ & $0.59 \pm 0.07 b c$ & $0.04 \pm 0.03 b$ & $5.66 \pm 2.72 \mathrm{de}$ & $7.94 \pm 0.09 \mathrm{ab}$ & $\begin{array}{l}2.24 \pm 0.41 d \\
e\end{array}$ \\
\hline
\end{tabular}




\begin{tabular}{|c|c|c|c|c|c|c|}
\hline $\begin{array}{c}\text { Text } \\
\text { water }\end{array}$ & 0 & 0.01 & 0.15 & 0.93 & 8.53 & 0.30 \\
\hline National & & & & & & \\
\hline $\begin{array}{c}\mathrm{V} \\
\text { standard }\end{array}$ & $\leq 40$ & $\leq 2$ & $\leq 0.4$ & - & $6-9$ & - \\
\hline
\end{tabular}

Note: the same column data is marked with different lower case letters, indicating significant difference $(P<0.05) . " * "$ indicates that the water quality parameters are beyond the national standards for the quality of the surface water environment of the state $\mathrm{V}$.

It can be seen from Table 7 that the concentration of COD, ammonia nitrogen, total $\mathrm{P}, \mathrm{SS}$, and EC in the surface runoff of the two control substrates are the average values of the matrix product and the mixed matrix formulation of vermiculite and fly ash in a volume ratio of 2:3:3. Lower, and in line with the national surface water environment, Class V standards. In terms of COD concentration, except for T22 treatment, the COD concentrations of the other treated substrates were significantly higher than those of the two controls, and the levels exceeded. In the ammonia nitrogen concentration, the ammonia nitrogen content of all treated substrates met the standard, and the ammonia nitrogen content of T12, T22 and T42 treatments was not significantly different from that of the two controls at the 0.05 level. In the total $\mathrm{P}$ concentration, the total $\mathrm{P}$ content of all treated substrates met the standard, and the total P content of the T22 treatment was not significantly different from that of the two controls at the 0.05 level. In terms of SS concentration, only the SS content of the substrate treated withT12 and T22 was not significantly different from that of the two controls at the 0.05 level, and the other treatments were significantly higher than the two controls. In terms of $\mathrm{pH}$ value, all treatments reached the national surface water environmental quality class $\mathrm{V}$ standard, and the $\mathrm{pH}$ values of the $\mathrm{T} 32$ and $\mathrm{T} 42$ treatment substrates were significantly higher than the $0.05 \%$ of the CK12. However, the difference between CK22 was not significant, and the $\mathrm{pH}$ of the T12 treatment substrate was significantly higher than that of the grass carbon CK12 at the 0.05 level. In terms of EC value, except for T22 and T42 treatments, EC values of the remaining treatment matrix were significantly higher than the two controls at the 0.05 level.

\section{Conclusion}

(1) The retention rate of the matrix to runoff water increases with the increase of the proportion of the inorganic substrate added to the same kind of substrate product. And the composite matrix formed by the ratio of the browning coal as the auxiliary material of matrix material to the retention capacity of run-off water is stronger than the compound matrix formed by the ratio of the matrix material of the auxiliaries of peat. The highest retention rate of T122 matrix was $72.2 \%$.

(2) The composite matrix obtained with different ratios of substrate product and inorgani matrix is slightly less than the peat and pastoral soil in terms of water storage capacity, in which the substrate product ( $\mathrm{V}$ lignite: $\mathrm{V}$ cow dung: $\mathrm{V}$ straw $=$ The ratio of 1:2:6) to the inorganic matrix gives the matrix the best water storage capacity in the formulation of the mixed matrix and is comparable to that of peat.

(3) The COD in the runoff of the roof cultivation substrate obtained with the different ratios of the substrate product and the inorganic substrate is in addition to the $\mathrm{FH} 2 \mathrm{w}$ treatment substrate, and the rest of the treatment substrates exceed the national surface water environment quality class $\mathrm{V}$ standard; the substrate product and vermiculite, powder In the 1:1:1 volume ratio of fly ash mixed matrix formulation, ammonia nitrogen and $\mathrm{P}$ total $\mathrm{pH}$ of the runoff water of the T21, C11 and T41 
substrates met the standard; In the mixed matrix formulation with the volume ratio of vermiculite and fly ash of 2:3:3, the ammonia nitrogen, $\mathrm{P}$ total $\mathrm{pH}$ of the runoff water quality of all treated substrates met the standard. The SS concentration in runoff water quality of T12 and T22 substrates was not significantly different from that of peat and pasture soil. T12, T32 and T42 substrates had significantly higher $\mathrm{pH}$ values than peat and could better neutralize acid rain in nature. The EC values of runoff water quality of T11, T22 and T42 treated substrates were not significantly different from those of peat and arable soil.

Therefore, the comprehensive indicators found that with the increase of the depth of the same matrix, the storage capacity of the matrix is stronger. Finally, three more ideal matrix formulations were selected: T222 [V \{substrate product (V lignite: V cow manure: V straw = 2:1:6) \}: V vermiculite: $\mathrm{V}$ fly ash $=2: 3: 3$ ] optimal, followed by T122 [V $\{$ substrate product (V lignite: $\mathrm{V}$ cow manure: $\mathrm{V}$ straw $=1: 2: 6)\}: \mathrm{V}$ vermiculite: $\mathrm{V}$ fly ash $=2: 3: 3]$ and T422 [V $\{$ Substrates (V peat: V Cow manure: V Stalk $=2: 1: 6)\}$ : V Vermiculite: V fly ash $=2: 3: 3]$.

\section{Acknowledgements}

Shuai Hao and Yihe Zhu are authors contributed equally. This work was financially supported by Project of Key Laboratory of Urban Agriculture( North China) in 2018(Grant N0. Kf20180**), 2018 Science and Technology Project-Research and Demonstration of Cow Manure Substrate Utilization Technology (20180112) Support Project for the Construction of 2019 Shiyuan Hui Vegetable Farms-Integrated Demonstration of Soil Fertility Support Technology (PXM2017_036205_000028); Beijing Dairy Industry Innovation Team (BAIQ6-2018).

\section{References}

[1] PU ShengHai, FENG GuangPing, LI Wei et al. Determination of physicochemical properties of soilless culture medium and its application[J]. Xinjiang Agricultural Sciences, 2012, 49(2): 267 272

[2] QIU Qiu-tu. Application of Membrane Bioreactor (MBR) in Wastewater Treatment[J]. Energy and Environment, 2014(5): 78. 